\title{
Smartphones Addiction and its Correlates among University Students, Egypt
}

\author{
Mariam G Abd-Elnaser ${ }^{1}$, Dalia G Mahran*1, Hosnia S Abd El-Mageed ${ }^{1}$ and Ghaydaa Shehata ${ }^{2}$ \\ ${ }^{1}$ Department of Public Health and Community Medicine, Assiut University, Assiut, Egypt \\ ${ }^{2}$ Department of Neurology and Psychiatry, Assiut University, Assiut, Egypt
}

*Corresponding author: Dalia G. Mahran, Professor, Department of Public

Health and Community Medicine, Assiut University, Assiut, Egypt.

Received Date: September 02, 2020

Published Date: September 22, 2020

\footnotetext{
Abstract

Introduction: Smartphones addiction is a common problem, especially among adolescents. It has been linked with potential health related hazards and psychological disorders. There is not enough data about the size of the problem in Egypt

Study objectives: to determine prevalence and correlates of smartphones addiction among Assiut University students.

Material and methods: A cross-sectional study was conducted including 700 Assiut University students. They were selected randomly by using a multistage stratified cluster sampling technique. Data were collected by using four sections self-administered questionnaire including the students' demographic data, the pattern of smartphone use, assessment of depression symptoms and smartphones addiction by Arabic version of smartphones addiction scale.

Results: Smartphones addiction prevalence was 44.7\%. Multivariate logistic regression found that smartphones addiction increased significantly in males $(\mathrm{OR}=1.8 \& \mathrm{P}$-value $=0.002)$, use time of smartphone more than four hours daily $(\mathrm{OR}=2.4 \& \mathrm{P}$ - value $=0.004)$ and self-reporting as smartphones addict $(\mathrm{OR}=12.2 \& \mathrm{P}$ - value $<0.001)$. Also, it increased with severe depression symptoms $(\mathrm{OR}=6.0 \& \mathrm{P}$ - value $<0.001)$, moderately severe depression symptoms $(\mathrm{OR}=3.4 \& \mathrm{P}-$ value $<0.001)$ and $(\mathrm{OR}=2.8 \& \mathrm{P}$ - value $<0.001)$ with moderate depression symptoms.

Conclusion: Smartphones addiction was highly prevalent among the sampled Egyptian students. Male gender, using smartphones more than four hours daily, self-reporting as smartphone addict and depression symptoms were found to be predictors of smartphones addiction. Students awareness programs should be planned about possible early warnings and potential consequences of smartphones use.

Keywords: Smartphones; Addiction; University students; Egypt

Abbreviations: FAS: Family Affluence Scale; SAS-A: Arabic Version of Smartphones Addiction Scale; PHQ-9: Patient Health Questionnaire-9; SNW: Social Networks
}

\section{Introduction}

Smartphones have become a part of our daily life, the number of people using smartphones continues to increase day after day. Easy access to internet is the main advantage of smartphones in comparison to traditional mobile phones, so they are considered as handheld convenient substitutes to computers [1]. People use smartphones for many purposes such as entertainment, communication, education, browsing for information or business facilitation. Unfortunately the excessive use of smartphones makes people 'addicted' to that type of technology [2]. Past research has shown that older people have less positive attitudes towards a variety of technologies and they are less likely than younger people 
to embrace new technology [3], so it seems that the problem of smartphones addiction is most likely to affect adolescents who are fascinated with new technologies. Generally, smartphone addiction consists of four main components: compulsive phone use: behaviors such as repeated checking for updates or messages, withdrawal: feelings of distress without the phone, tolerance: longer bouts of use, functional impairment: interference with other life activities and social relationships [4]. There are many psychological factors related to smartphones addiction such as anxiety, stress, poor social and family relationship, depression, loneliness, shyness, degree of self-esteem and satisfaction with life [5-7]. Studies have also shown the adverse effects of smartphones addiction on quality of sleep [5], physical activity [8] and academic performance [9]. Smartphones addiction also have harmful physical consequences like headache, blurred vision, neck and shoulder pain and impairment of hand function [10-12]. There are not enough available researches about smartphones addiction among young people in Egypt. This study attempts to determine size of this problem, its possible risk factors and its adverse effects on different aspects.

\section{Material and Methods}

A cross-sectional study was conducted at Assiut University, Egypt. The students who own smartphones were the target population.

\section{Sample design}

Target students were selected randomly by using a multistage stratified cluster sampling technique.

At the first stage, Faculties within Assiut University were stratified into 3 strata; Practical, Theoretical and Medical faculties, then faculties were chosen randomly from each stratum to end up with 5 faculties: one medical faculty "Faculty of Pharmacy", two practical faculties "Faculty of Agriculture and Faculty of Education Kindergarten" and two theoretical faculties "Faculty of Social Service and Faculty of English Commerce". At the second stage, a cluster sample was chosen from the third academic year within each faculty. The clusters were chosen through simple random sample.

\section{Sample size}

Sample size was calculated using Epi- Info, version 7. according to the student affairs administration, the total number of registered students at Assiut University was 61293. Based on previous study in Saudi Arabia [13] the prevalence of smartphones addiction was $29.6 \%$. With a power of $80 \%$ and a confidence level of $95 \%$ and design effect of 2 , the calculated sample for the study was estimated to be about 630 students. To compensate the drop outs, $10 \%$ were added giving a final sample size of about 700 students. The sample was distributed proportionally between the selected faculties.

\section{Data collection tool and technique}

Data were collected through self-administered questionnaire, the questionnaire was consisted from 4 parts: The first section includes the demographic data of the students as: age, sex, number of family members and residence, socioeconomic status which was measured by family affluence scale (FAS) in addition to parents' education and occupation. FAS consists of four questions with three point ordinal scale, where FAS low (score $=0,1,2$ ) indicates low affluence, FAS medium (score $=3,4,5$ ) indicates middle affluence, and FAS high (score=6,7,8,9) indicates high affluence [14]. The second section described pattern of smartphone use as: daily use time and different purposes of use (social networks browsing, entertainment, education, etc.). The third section was designed for determination of smartphone addiction by the use of Arabic version of smartphones addiction scale (SAS-A) [13], The SAS-A is a self-completed, 6-point Likert-type scale with 10 items. Each question has a response scale from 1 to $6(1=$ strongly disagree to $6=$ strongly agree), reflecting the frequency of the symptoms. The cut- off value was 31 for males and 33 for females. The fourth section assessed depression by patient health questionnaire- 9 (PHQ-9), it consists of 9 questions which inquire the experience of the items in the past 2 weeks and each item is scored from zero (not at all) to three (nearly every day) [15].

\section{Data management and statistical analysis}

The completed students' questionnaires were revised and data management including data entry, cleaning and statistical analysis were carried out using SPSS version 20. Descriptive statistics were done in the form of frequencies, mean and SD then suitable tests of significance as Mann-Whitney test, chi square and multivariate logistic regression models were done. Values were considered significant when P-values equal or less than 0.05 .

\section{Ethical considerations}

The proposal was approved via the Ethical Review Committee at Assiut Faculty of Medicine before starting data collection. Administrative permission was obtained from the University authority and written informed consent was obtained from participating students (at the front page of the questionnaire).

\section{Results}

The mean age \pm SD of the students was $21.27 \pm 0.88$ years ranged from19-25 years. Males and females constituted $40.1 \%$ and $59.9 \%$ of the students respectively. Students in medical faculty (Faculty of Pharmacy) represented $16 \%$ while in practical faculties (Faculty of Agriculture and Faculty of Education Kindergarten) and theoretical faculties (Faculty of Social Service and Faculty of English Commerce) represented 29\% and 55\% respectively. As regard smoking, $8 \%$ of the studied students were current smokers either daily or not daily, $2.1 \%$ of students were ex-smokers and the majority of students $(89.8 \%)$ never smoke. As regards their residence, $53.4 \%$ and $46.6 \%$ were urban and rural respectively. More than half of the students belonged to medium to high socioeconomic status families (59.25\%). While only $6.2 \%$ of students' fathers and $19.2 \%$ of mothers were illiterate, higher percentages of students' parents educated to university and post graduate level $(46.3 \%$ of 
fathers and $31.9 \%$ of mothers). As regards parents' work, $28.9 \%$ of the fathers' jobs were professional and $27.1 \%$ were employee. While mothers' jobs were housewife in $63.8 \%$ of the studied group, mothers who work in professional work and as employee represent $19.6 \%$ and $13.2 \%$ respectively.
The studied students were classified by SAS-A into 2 categories: $44.7 \%$ of them were smartphones addict and $55.3 \%$ were non addict, the percentage of smartphones addiction was higher in males than in females (50.2\% versus $41.1 \%)$ with statistical significant difference (P-value $=0.017)$ (Figure 1$)$.

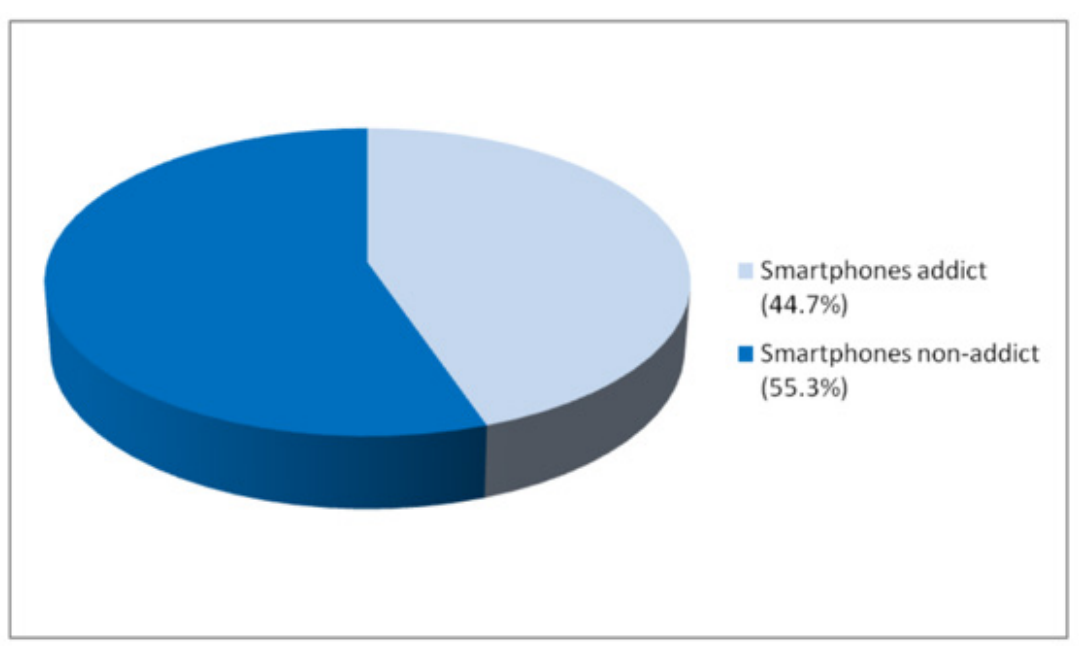

Figure 1: Prevalence of smartphones addiction among the studied students in Assiut University, 2018.

There were no statistical significant differences as regards residence, family size and socioeconomic status, parents' education and occupation or smoking status between smartphoneaddicts and non-addicts. There was no statistical significant association between smartphones addiction and duration of owing smartphones, but there was significant difference between average daily use of smartphones in smartphones addicts and non addicts, smartphones addiction was higher in students using their smartphones more than four hours daily $(58.5 \% \&$ P-value < 0.001$)$ compared to those using their smartphones for 2-4 hours daily or less than two hours daily ( $36.8 \%$ \& $18.7 \%$ respectively). Percent of smartphones addiction level was statistically significant higher in students who always check their smartphones after waking up and before sleep (65.8\% \& 61.8\%) compared to those who don't $(29.4 \%$ $\& 22.8 \%) \&(\mathrm{P}$-value< 0.001$)$. Smartphones addict students use their smartphones during lectures\& practical classes and during driving or crossing the streets more than non addicts and the difference is statistically significant (P-value $<0.001$ ). Smartphones addiction level was higher in students who already considered themselves as smartphones addicts (P-value< 0.001) (Table 1).

Percent of the students using their smartphones just to pass time or to scroll social networks as Facebook and Twitter were higher in the smartphone addict students compared to non-addict students and the difference were highly statistically significant regarding the three purposes (P-value $<0.001$ ) (Table 2).

There was statistical highly significant association between the three studied adverse effects of smartphones use and smartphones addiction, percentage of students reported less physical exercise, negative effect on academic performance and spending less time with family due to use of smartphones was higher in smartphones addict group compared to non-addicts (Table 3).

There was highly significant association between smartphones addiction and depression symptoms. The percent of smartphones addiction increased gradually from $25.2 \%$ in students with no depression symptoms to $72.9 \%$ in students with severe depression symptoms (P-value >0.001) (Figure 2).

By using multivariate logistic regression analysis, significant predictors of smartphone addiction were male gender, using smartphone more than four hours per day, self-reporting as smartphones addict and different degrees of depression symptoms; severe, moderately severe and moderate depression symptoms (Table 4).

Table 1: Relationship between pattern of smartphones use and smartphones addiction among the studied students in Assiut University, 2018.

\begin{tabular}{|c|c|c|c|c|c|}
\hline \multirow{2}{*}{ Smartphones Use } & \multicolumn{2}{|c|}{ Smartphones Addict (No.=313) } & \multicolumn{2}{|c|}{ Smartphones Non-Addict $($ No. $=387)$} & \multirow[b]{2}{*}{ P-Value* } \\
\hline & No. & $\%$ & No. & $\%$ & \\
\hline \multicolumn{6}{|c|}{ Own smartphone for" } \\
\hline - $\quad<1$ year & 21 & 53.8 & 18 & 46.2 & \multirow[b]{3}{*}{0.092} \\
\hline - $1-3$ years & 66 & 38.2 & 107 & 61.8 & \\
\hline - $\quad>3$ years & 225 & 46.2 & 262 & 53.8 & \\
\hline
\end{tabular}




\begin{tabular}{|c|c|c|c|c|c|c|}
\hline \multicolumn{7}{|c|}{ Average daily use $\mathrm{e}^{\#}$} \\
\hline$\bullet$ & $<2$ hours & 25 & 18.7 & 109 & 81.3 & \multirow{3}{*}{$<0.001$} \\
\hline$\bullet$ & 2-4 hours & 71 & 36.8 & 122 & 63.2 & \\
\hline$\bullet$ & $>4$ hours & 213 & 58.5 & 151 & 41.5 & \\
\hline \multicolumn{7}{|c|}{ Checking immediately after waking up } \\
\hline$\bullet$ & All the time & 133 & 65.8 & 69 & 34.2 & \multirow{4}{*}{$<0.001$} \\
\hline & Most of times & 54 & 46.6 & 62 & 53.4 & \\
\hline$\bullet$ & Sometimes & 91 & 34.6 & 172 & 65.4 & \\
\hline • & No & 35 & 29.4 & 84 & 70.6 & \\
\hline \multicolumn{7}{|c|}{ Checking before sleep" } \\
\hline$\bullet$ & All the time & 207 & 61.8 & 128 & 38.2 & \multirow{4}{*}{$<0.001$} \\
\hline & Most of times & 54 & 35.8 & 97 & 64.2 & \\
\hline$\bullet$ & Sometimes & 39 & 25.0 & 117 & 75.0 & \\
\hline$\bullet$ & No & 13 & 22.8 & 44 & 77.2 & \\
\hline \multicolumn{7}{|c|}{ Using during lectures or practical classes" } \\
\hline$\bullet$ & All the time & 50 & 65.8 & 26 & 34.2 & \multirow{4}{*}{$<0.001$} \\
\hline$\bullet$ & Most of times & 37 & 63.8 & 21 & 36.2 & \\
\hline$\bullet$ & Sometimes & 121 & 50.6 & 118 & 49.4 & \\
\hline$\bullet$ & No & 103 & 32.1 & 218 & 67.9 & \\
\hline \multicolumn{7}{|c|}{ Using during driving or passing the street ${ }^{\#}$} \\
\hline & All the time & 26 & 74.3 & 9 & 25.7 & \multirow{4}{*}{$<0.001$} \\
\hline & Most of times & 20 & 64.5 & 11 & 35.5 & \\
\hline & Sometimes & 94 & 51.6 & 88 & 48.4 & \\
\hline$\bullet$ & No & 171 & 38.2 & 277 & 61.8 & \\
\hline \multicolumn{7}{|c|}{ Self-reporting as smartphone-addict ${ }^{\#}$} \\
\hline & Yes & 110 & 78.6 & 30 & 21.4 & \multirow{4}{*}{$<0.001$} \\
\hline$\bullet$ & Maybe & 137 & 52.9 & 122 & 47.1 & \\
\hline$\bullet$ & Don't know & 25 & 39.1 & 39 & 60.9 & \\
\hline$\bullet$ & No & 36 & 15.6 & 195 & 84.4 & \\
\hline
\end{tabular}

${ }^{*}$ Chi-square test was used

\#Missing values were present (ranged from 1-9) \& valid percent was used

Table 2: Relationship between main purpose of smartphones use and smartphones addiction among the studied students in Assiut University, 2018.

\begin{tabular}{|c|c|c|c|c|c|}
\hline \multirow{2}{*}{ Main purpose } & \multicolumn{2}{|c|}{ Smartphones addict $($ No. $=313)$} & \multicolumn{2}{|c|}{ Smartphones non-addict $($ No. $=387)$} & \multirow[b]{2}{*}{ P- value* } \\
\hline & No. & $\%$ & No. & $\%$ & \\
\hline \multicolumn{6}{|c|}{ Necessary calls } \\
\hline - $\quad$ Yes & 171 & 37.7 & 283 & 62.3 & \multirow{2}{*}{$<0.001$} \\
\hline - $\quad$ No & 142 & 57.7 & 104 & 42.3 & \\
\hline \multicolumn{6}{|l|}{ Texting } \\
\hline - $\quad$ Yes & 193 & 47.1 & 217 & 52.9 & \multirow{2}{*}{0.122} \\
\hline - $\quad$ No & 120 & 41.4 & 170 & 58.6 & \\
\hline \multicolumn{6}{|c|}{ Scrolling social networks as Facebook and Twitter } \\
\hline - $\quad$ Yes & 233 & 51 & 224 & 49.0 & \multirow{2}{*}{$<0.001$} \\
\hline - $\quad$ No & 80 & 33.3 & 163 & 66.7 & \\
\hline \multicolumn{6}{|c|}{ Education } \\
\hline - $\quad$ Yes & 145 & 41.4 & 205 & 58.6 & \multirow{2}{*}{0.081} \\
\hline - $\quad$ No & 168 & 48.0 & 182 & 52.0 & \\
\hline \multicolumn{6}{|c|}{ Checking news, weather, etc } \\
\hline - Yes & 74 & 49.3 & 76 & 50.7 & \multirow{2}{*}{0.199} \\
\hline - $\quad$ No & 239 & 43.5 & 311 & 56.5 & \\
\hline
\end{tabular}




\begin{tabular}{|c|c|c|c|c|c|c|}
\hline \multicolumn{7}{|c|}{ Games } \\
\hline & Yes & 86 & 42.8 & 115 & 57.2 & \multirow{2}{*}{0.532} \\
\hline & No & 227 & 45.5 & 272 & 54.5 & \\
\hline \multicolumn{7}{|c|}{ Just passing time } \\
\hline & Yes & 77 & 58.8 & 54 & 41.2 & \multirow{2}{*}{$<0.001$} \\
\hline & No & 236 & 41.5 & 333 & 58.5 & \\
\hline \multicolumn{7}{|c|}{ Others } \\
\hline & Yes & 7 & 43.8 & 9 & 56.3 & \multirow{2}{*}{0.937} \\
\hline & No & 306 & 44.7 & 378 & 55.3 & \\
\hline
\end{tabular}

Chi-square test was used

Table 3: Relationship between possible adverse effects of smartphones use and smartphones addiction among the studied students in Assiut University, 2018.

\begin{tabular}{|c|c|c|c|c|c|}
\hline \multirow{2}{*}{ Adverse effects } & \multicolumn{2}{|c|}{ Smartphones addict (No.=313) } & \multicolumn{2}{|c|}{ Smartphones non-addict (No.=387) } & \multirow[b]{2}{*}{ P-value* } \\
\hline & $\mathbf{N}$ & $\%$ & $\mathbf{N}$ & $\%$ & \\
\hline \multicolumn{6}{|c|}{ * Physical effects } \\
\hline \multicolumn{6}{|c|}{ Less physical exercise due to smartphone use ${ }^{\#}$} \\
\hline - $\quad$ Yes & 137 & 53.5 & 119 & 46.5 & \multirow{3}{*}{$<0.001$} \\
\hline - $\quad$ No & 111 & 33.7 & 218 & 66.3 & \\
\hline - $\quad$ Can't decide & 64 & 58.2 & 46 & 41.8 & \\
\hline \multicolumn{6}{|c|}{ * Effect on achievement } \\
\hline \multicolumn{6}{|c|}{ Perceived adverse effect on academic performance due to smartphone use ${ }^{\#}$} \\
\hline - $\quad$ Yes & 177 & 57.8 & 129 & 42.2 & \multirow{3}{*}{$<0.001$} \\
\hline - $\quad$ No & 85 & 28.8 & 210 & 71.2 & \\
\hline - $\quad$ Can't decide & 51 & 52.6 & 46 & 47.4 & \\
\hline \multicolumn{6}{|c|}{ * $\quad$ Effect on family relationships } \\
\hline \multicolumn{6}{|c|}{ Spending less time with family due to smartphone use ${ }^{\#}$} \\
\hline - $\quad$ Yes & 223 & 58.2 & 160 & 41.8 & \multirow{3}{*}{$<0.001$} \\
\hline - $\quad$ No & 58 & 24.3 & 181 & 75.7 & \\
\hline - Can't decide & 30 & 40.5 & 44 & 59.5 & \\
\hline
\end{tabular}

${ }^{*}$ chi square test was used

\#Missing values were present (ranged from 2-5) \& valid percent was used

Table 4: Logistic regression analysis for predictors of smartphones addiction among studied students in Assiut University, 2018.

\begin{tabular}{|c|c|c|}
\hline Variable & P-value & Odds Ratio (95\% Confidence Interval) \\
\hline \multicolumn{3}{|l|}{ Gender (reference: females) } \\
\hline - $\quad$ Males & 0.002 & $1.822(1.254-2.648)$ \\
\hline Average daily use & 0.004 & \\
\hline - $\quad<2$ hours daily(reference) & & \\
\hline - 2-4 hours daily & 0.299 & $1.388(0.747-2.58)$ \\
\hline - $\quad>4$ hours daily & 0.004 & $2.365(1.307-4.279)$ \\
\hline Self-reporting as addict & $<0.001$ & \\
\hline - Yes & $<0.001$ & $12.167(6.622-22.356)$ \\
\hline - $\quad$ Maybe & $<0.001$ & $4.273(2.624-6.957)$ \\
\hline - Don't know & 0.006 & $2.556(1.302-5.018)$ \\
\hline - $\quad$ No (reference) & & \\
\hline Depression symptoms & $<0.001$ & \\
\hline - $\quad$ None (reference) & & \\
\hline - $\quad$ Mild & 0.126 & $1.535(0.887-2.655)$ \\
\hline
\end{tabular}




\begin{tabular}{|c|c|c|}
\hline$\bullet \quad$ Moderate & 0.001 & $2.812(1.555-5.086)$ \\
\hline$\bullet \quad$ Moderately severe & 0.001 & $3.409(1.677-6.928)$ \\
\hline$\bullet \quad$ Severe & $<0.001$ & $6.015(2.525-14.329)$ \\
\hline Loneliness score & 0.379 & $1.049(0.943-1.168)$ \\
\hline Main purpose is social network & 0.493 & $1.155(0.765-1.743)$ \\
\hline Main purpose is passing time & 0.862 & $1.042(0.657-1.653)$ \\
\hline Constant & $<0.001$ & \\
\hline
\end{tabular}

* Significant $p>0.05$ Nagelkerke R Square $=0.367 \mathrm{~N}=700$

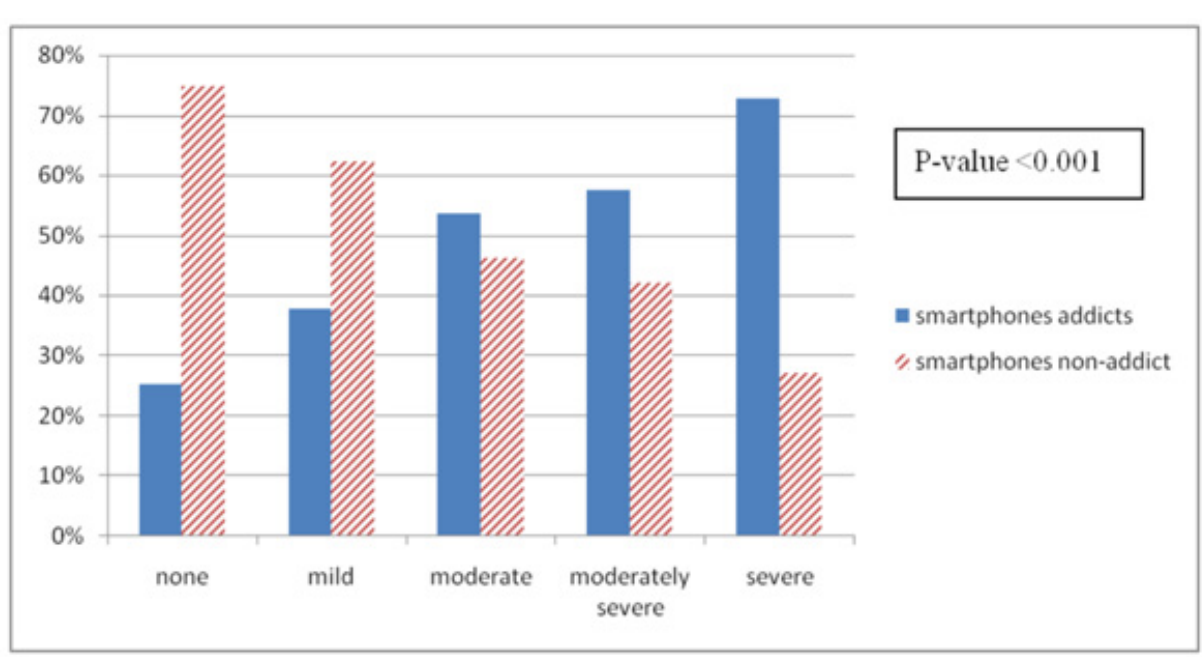

Figure 1: Relationship between depressive symptoms and smartphones addiction among studied students in Assiut University, 2018.

\section{Discussion}

Several studies have investigated the prevalence of smartphone addictive behaviors, which also can be called mobile phone problematic use, among young age groups. Prevalence of smartphones addiction in this study was $44.7 \%$, this percent is lower than that reported by a study conducted among 420 students, with mean age 19.7 years, from different faculties of physical therapy in Egypt at 2018 in which $62.4 \%$ of students were smartphones addict [16]. Both studies are similar in that smartphones addiction was assessed in both studies by Arabic version of smartphones addiction scale (SAS-A), but they differ in that the current study was conducted on representative sample of students from different types of faculties. A cross-cultural study comparing university students in four Middle Eastern countries: Sudan, Jordan, Saudi Arabia, and Yemen was conducted in January, 2019 to compare smartphones addiction prevalence among these countries using SAS-A. The prevalence of smartphones addiction was higher in Jordan (59.8\%) compared to our study, but lower in Saudi Arabia (27.2\%), Sudan (17.3\%), and Yemen (8.6\%). The overall prevalence in the four countries was $27.7 \%$ [17]. A crosssectional study was conducted at Wannan Medical College, China in 1441 undergraduate students, found $29.8 \%$ prevalence of smartphone addiction [18], the lower prevalence could be due to the inclusion of medical students only with possibility of having more time in studying than to use smartphones. On other study included 210 Korean female university students with mean age 22 years, revealed that $30.5 \%$ had high risk to smartphone addiction [19].

In five schools in London, UK, a prevalence of problematic users was $10 \%$ out of 1026 students assessed by the mobile phone problematic use scale [20]. Differences in prevalence of smartphones addiction level among countries may be due to differences in the prevalence of smartphone ownership between countries, differences in the extent of accessibility to the internet and Wi-Fi coverage. Also, different life style characters as nature of work, how to spend spare time, nature of study between school and university and also between faculties, etc. across different countries and studies. Furthermore, different methodologies, different tools and questionnaires are used to assess smartphones addiction and different sampling techniques and sample characteristics.

In the current study, smartphones addiction was significantly associated with male gender, this is consistent with many studies found that smartphones addiction is higher among males than females, as in two studies conducted on university students in Saudi Arabia [21,22]. Males use smartphones more often than females and tend to be likely to be negatively affected by smartphones. This result also could be attributed to the fact that female students tend to study harder, thus spending less time using smartphones, than male students in line with a study suggested that academic performance of females is better than males [23]. On the other 
hand, other studies found that females are more likely to develop dependency on or addiction to mobile phones as two studies done in Taiwan and Australia [24,25]. This could be attributed to that the female adolescents are more involved in communication with others via their smartphones [24]. However, it has been reported recently that the gender gap in cellular phone usage has practically vanished [26]. The differences may well exist in how males and females use their smartphones $[27,28]$. Males are likely to be more interested in the technological aspects of the cell phones, whereas females are more concerned with social interaction [29]. Data revealed significant differences in smartphone addiction in favor of participants who use smartphones for more than 4 hours a day. It seems that the longer the time individuals spend on the smartphone, the more likely to be smartphone addicts as overuse creates a habit. Young explained that the more individuals experience a sense of immersion in the internet, the more they will become further immersed, so excessive internet use can lead to dependence [30]. It is possible that the same principle applies to smartphone use. This finding is consistent with many studies reported that individuals using smartphones for longer time periods are more likely to be smartphone addicts as a study done in as in the study done in Saudi Arabia conducted on 416 students, both male and female, at King Saud University [21] and another study conducted on 203 sixthyear medical students at the Faculty of Medicine, King Abdulaziz University, Jeddah, Saudi Arabia, during July 2017 [22], also a study conducted on 1,236 smartphone-using students from six universities in Suwon, South Korea [31].

Also, the results showed that percent of students using their smartphones just to pass time or to scroll social networks (SNW) as Facebook and Twitter was significantly higher in the smartphones addict students compared to non-addict students. This is consistent with a Korean study that indicated that social network use is a stronger predictor of smartphone addiction than game usage [32]. Another study in Saudi Arabia found that three-quarters of the participants use at least four applications daily, mainly for SNW and watching news [33]. A recent study conducted in Korea found that the smartphone addiction group used the mobile messenger, SNW, and internet for significantly longer duration when compared to the normal user group [34].

In this study, depression symptoms were significantly associated with smartphones addiction on bivariate analysis, furthermore, they were found to be significant predictors of smartphones addiction. These findings are consistent with prior results from multiple studies. In a sample of 353 Korean college students, depression was reported as a significant independent positive predictor of smartphone addiction [35]. Depressive state was revealed in a survey of 126 Japanese medical university students as an independent predictor of immersion in internet communication score [36]. Mean depression score were significantly higher among high versus low smartphone users, and emerged as independent predictors of smartphones addiction severity as per findings from a survey of 319 Turkish university students [5].

Less physical exercise was reported to be due to excessive smartphones use by $36.8 \%$ of the participant students and found to be significant association. This is consistent with many studies; a study conducted by Kim et al. (2015) in Korea found that smartphone addiction was associated with less physical activity, such as daily walking [8]. Another study in Saudi Arabia, conducted on 2367 university students reported that at least $30 \%$ of the study participants agreed that they had a less healthy lifestyle since they began using their smartphones such as, more fast food and less exercise [33]. In this study, 43.8\% of students reported significant association between adverse effect on their academic performance and smartphones use. Using smartphones during lectures and practical classes make students lose their concentration, also students can't focus on their lessons with constant checking of notifications from multiple applications on smartphones during study. The current study found that more than half of students reported using their smartphones during lectures or practical classes and $41.3 \%$ of students reported having hard concentration in class due to excessive smartphones use. This is consistent with what was reported by a study in Riyadh in which approximately $25 \%$ of the study participants found that their academic achievement had been adversely affected since they started using their smartphones [33]. In a USA study conducted on 536 undergraduate students, increased smartphone use was associated with decreased academic performance [37]. A Korean study found that high addiction level was associated with low level of self-regulated learning [19]. This study has some limitations, the self-reported data could be subjected to reporting bias (over reporting / recall bias). Also the type of the study is cross-sectional, so we couldn't judge the causal relation between outcome and predictors.

\section{Conclusion}

Smartphones addiction is highly prevalent among Assiut University students. Male gender, using smartphones more than 4 hours daily, self-reporting as smartphones addict and severe depression symptoms were significant correlates for smartphones addiction. Awareness programs about possible early warnings and potential consequences of smartphones addiction should be planned for university students. Also, more researches are required to assess the effects of mobile phones on different systems of the human body along with clinical examination.

\section{Acknowledgment}

Great thanks to the competent research field assistants, Mennat-Allah Gamal and Mohamed Abd Al-Lateef for helping in data collection.

\section{Disclosure}

The authors declare that there was no conflict of interest. 


\section{References}

1. Zheng P, Ni Lionel (2010) Smart Phone and Next Generation Mobile Computing. Morgan Kaufmann Publishers Inc. San Francisco, CA, USA

2. Kuss D, Griffiths M, Karila L, Billieux J (2014) Internet Addiction: A Systematic Review of Epidemiological Research for the Last Decade. Current Pharmaceutical Design 20(25): 4026-4052.

3. Brickfield CF (1984) Attitudes and perceptions of older people. In Robinso PK, Birren JE (Eds.), Aging and technological advances. New York: Plenum, USA, pp. 31-38.

4. Lin $\mathrm{YH}$, Lin $\mathrm{YC}$, Lee $\mathrm{YH}$, Lin $\mathrm{PH}$, Lin $\mathrm{SH}$, et al. (2015) Time distortion associated with smartphone addiction: Identifying smartphone addiction via a mobile application (App). Journal of Psychiatric Research 65: $139-145$

5. Demirci K, Akgönül M, Akpinar A (2015) Relationship of smartphone use severity with sleep quality, depression, and anxiety in university students. Journal of Behavioral Addictions 4(2): 85-92.

6. Bian M, Leung L (2015) Linking Loneliness, Shyness, Smartphone Addiction Symptoms , and Patterns of Smartphone Use to Social Capital. Social Science Computer Review 33(1): 61-79.

7. Hawi NS, Samaha M (2017) Relationships among smartphone addiction, anxiety, and family relations. Behaviour \& Information Technology 36(10): 1-7.

8. Kim SE, Kim JW, Jee YS (2015) Relationship between smartphone addiction and physical activity in Chinese international students in Korea. Journal of behavioral addictions 4(3): 200-205.

9. Hawi NS, Samaha M (2016) To excel or not to excel: Strong evidence on the adverse effect of smartphone addiction on academic performance. Computers \& Education 98: 81-89.

10. Kivanc SA, Budak BA, Ulusoy MO, Olcaysu 00, Yesilirmak N (2017) Relation between Smartphone Use and Unilateral Ocular Pain and Headache'. In Current Perspectives on Less-known Aspects of Headache. Hande Turker, Intech Open.

11. Inal EE, Demirci K, Çetintürk A, Akgönül M, Savaş S (2015) Effects of smartphone overuse on hand function, pinch strength, and the median nerve. Muscle and Nerve 52(2): 183-188.

12. Kim HJ, Kim JS (2015) The relationship between smartphone use and subjective musculoskeletal symptoms and university students. Journa of physical therapy science 27(3): 575-579.

13. Alhassan M, Mulhim A Al, Sultan S, Alnofaily H, Alfayez M (2017) Smartphone Usage among Medical Students in Saudi Arabia. International Journal of Science and Research 6(1): 2227-2229.

14. Boyce W, Torsheim T, Currie C, Zambon A (2006) The family affluence scale as a measure of national wealth: Validation of an adolescent selfreport measure. Social Indicators Research 78(3): 473-487.

15. Kroenke K, Spitzer RL, Williams JBW (2001) The PHQ-9: Validity of a brief depression severity measure. Journal of General Internal Medicine 16(9): 606-613.

16. Soliman Elserty N, Ahmed Helmy N, Mohmed Mounir K (2018) Smartphone addiction and its relation to musculoskeletal pain in Egyptian physical therapy students. European Journal of Physiotherapy 22(2): 1-9.

17. Albursan IS, Al Qudah MF, Dutton E, Hassan EMAH, Bakhiet SFA, et al. (2019) National, Sex and Academic Discipline Difference in Smartphone Addiction: A Study of Students in Jordan, Saudi Arabia, Yemen and Sudan. Community Mental Health Journal 55(5): 825-830.

18. Chen B, Liu F, Ding S, Ying X, Wang L, et al. (2017) Gender differences in factors associated with smartphone addiction: a cross-sectional study among medical college students. BMC Psychiatry 17(1): 341.
19. Lee J, Cho B, Kim Y, Noh J (2015) Smartphone Addiction in University Students and its Implication for Learning. In: Chen G, Kumar V, Kinshuk, Huang R, Kong S (Eds.), Emerging Issues in Smart Learning. Lecture Notes in Educational Technology. Springer, Berlin, Heidelberg 297-298.

20. Networking S, Lopez-fernandez 0 (2013) Prevalence of Problematic Mobile Phone Use in British Adolescents. cyberpsychology behavior and social networking 17(2): 1-8.

21. Aljomaa SS, Qudah MF Al, Albursan IS, Bakhiet SF, Abduljabbar AS (2016) Smartphone addiction among university students in the light of some variables. Computers in Human Behavior 61: 155-164.

22. Alhazmi AA, Alzahrani SH, Baig M, Salawati EM, Alkatheri A (2018) Prevalence and factors associated with smartphone addiction among medical students at King Abdulaziz University, Jeddah. Pakistan Journal of Medical Sciences 34(4): 984-988.

23. N H TH (2016) Female Students get More Marks as Compared to Male Students: A Statistical Study. Journal of Business \& Financial Affairs 5(4).

24. Chiu SI, Hong FY, Chiu SL (2013) An Analysis on the Correlation and Gender Difference between College Students' Internet Addiction and Mobile Phone Addiction in Taiwan. ISRN Addiction (5): 1-10.

25. Walsh SP, White KM, Cox S, Young RM (2011) Keeping in constant touch: The predictors of young Australians' mobile phone involvement. Computers in Human Behavior 27(1): 333-342.

26. DeBaillon L, Rockwell P (2005) Gender and student-status differences in cellular telephone use. International Journal of Mobile Communications 3(1): 82.

27. Schudeleit T, Züst S, Weiss L, Wegener K (2016) Machine tool energy efficiency - A component mapping-based approach. International Journal of Automation Technology 10(5): 717-726.

28. Haverila MJ (2011) Cell phone feature preferences and gender differences among college students. International Journal of Mobile Communications ; $9(4): 401$.

29. Shade LR (2007) Feminizing the Mobile: Gender Scripting of Mobiles in North America. Continuum 21(2): 179-189.

30. Young KS. (1998) Caught in the net: how to recognize the signs of Internet addiction--and a winning strategy for recovery. $248 \mathrm{p}$.

31. Lee KE, Kim SH, Ha TY, Yoo YM, Han JJ, et al. (2016) Dependency on Smartphone Use and Its Association with Anxiety in Korea. Public Health Reports 131(3): 411-419.

32. Ahn H, Wijaya ME, Esmero BC (2014) A Systemic Smartphone Usage Pattern Analysis: Focusing on Smartphone Addiction Issue. International Journal of Multimedia and Ubiquitous Engineering 9(6): 9-14.

33. Alosaimi FD, Alyahya H, Alshahwan H, Al Mahyijari N, Shaik SA (2016) Smartphone addiction among university students in Riyadh, Saudi Arabia. Saudi Medical Journal 37(6): 675-683.

34. Cha SS, Seo BK (2018) Smartphone use and smartphone addiction in middle school students in Korea: Prevalence, social networking service, and game use. Health Psychology open 5(1): 2055102918755046.

35. Kim M, Kim H, Kim K, Ju S, Choi J, et al. (2015) Smartphone Addiction: (Focused Depression, Aggression and Impulsion) among College Students. Indian Journal of Science and Technology 8(25).

36. Toda M, Nishio N, Takeshita T, Toda M, Nishio N, et al. (2015) Predictive Factors for Smartphone Dependence: Relationship to Demographic Characteristics, Chronotype, and Depressive State of University Students. Open Journal of Preventive Medicine 5(12): 456-462.

37. Lepp A, Barkley JE, Karpinski AC (2015) The Relationship Between Cell Phone Use and Academic Performance in a Sample of US College Students. SAGE Open 5(1): 215824401557316. 